\title{
Review Article \\ Microevolutionary Effects of Habitat Fragmentation on Plant-Animal Interactions
}

\author{
Francisco E. Fontúrbel and Maureen M. Murúa \\ Departamento de Ciencias Ecológicas, Facultad de Ciencias, Universidad de Chile, Las Palmeras 3425, \\ Nuñoa, 7800024 Santiago, Chile \\ Correspondence should be addressed to Francisco E. Fontúrbel; francisco.fonturbel@gmail.com
}

Received 26 May 2014; Revised 4 August 2014; Accepted 8 August 2014; Published 25 August 2014

Academic Editor: Tomasz S. Osiejuk

Copyright (C) 2014 F. E. Fontúrbel and M. M. Murúa. This is an open access article distributed under the Creative Commons Attribution License, which permits unrestricted use, distribution, and reproduction in any medium, provided the original work is properly cited.

\begin{abstract}
Plant-animal interactions are a key component for biodiversity maintenance, but they are currently threatened by human activities. Habitat fragmentation might alter ecological interactions due to demographic changes, spatial discontinuities, and edge effects. Also, there are less evident effects of habitat fragmentation that potentially alter selective forces and compromise the fitness of the interacting species. Changes in the mutualistic and antagonistic interactions in fragmented habitats could significantly influence the plant reproductive output and the fauna assemblage associated with. Fragmented habitats may trigger contemporary evolution processes and open new evolutionary opportunities. Interacting parties with a diffuse and asymmetric relationship are less susceptible to local extinction but more prone to evolve towards new interactions or autonomy. However, highly specialized mutualisms are likely to disappear. On the other hand, ecological interactions may mutually modulate their response in fragmented habitats, especially when antagonistic interactions disrupt mutualistic ones. Ecoevolutionary issues of habitat fragmentation have been little explored, but the empiric evidence available suggests that the complex modification of ecological interactions in fragmented habitats might lead to nonanalogous communities on the long term.
\end{abstract}

\section{Introduction}

Plant-animal coevolution was described for the first time by Darwin $([1,2]$, but see [3]), relating the morphologic specificity between orchids and moths, stating that such precise correspondence could not be generated by chance. From Darwin's ideas, a wide conceptual framework has been developed regarding plant-animal coevolution $[4,5]$, from the perspective of the antagonistic (herbivory and parasitism) and mutualistic (pollination and seed dispersal) interactions. There is a growing body of literature regarding the importance of plant-animal interactions for the ecosystem functionality and stability. Moreover, those interactions are not constant over time; on the contrary, they are highly dynamic and susceptible to small and large temporal (ecological and geological times, resp.) and spatial (patch and landscape, resp.) scale disturbances.

In the last decades, human activities have led to habitat loss and fragmentation worldwide, causing the disruption of plant-animal mutualisms $[6,7]$ and the strengthening of some antagonisms [8-10]. While, in the last 15 years, the ecological consequences of habitat fragmentation have been studied in detail [11] but the microevolutionary aspects related to the change in ecological interactions have been little explored (but see [12]). This new research venue is of remarkable importance because, as the ecological conditions become modified through habitat loss and fragmentation processes, the ecological interactions on this novel scenario might rapidly evolve into new directions [7].

Understanding the consequences of habitat fragmentation on plant-animal interactions is important to describe general ecoevolutionary patterns that allow the construction of applied knowledge to be used for the maintaining of biodiversity. The aim of this review is to discuss the potential ecoevolutionary effects of habitat fragmentation on the modification of plant-animal interactions and community composition. For doing so, firstly we review how habitat fragmentation may lead to changes in microevolutionary forces experienced by the interacting species and the possible consequences of their evolutionary trajectory. Secondly, 
we review the differential effects of habitat fragmentation on antagonistic and mutualistic plant-animal interactions. Thirdly, we examine how multiple plant-animal interactions may interact, affecting plant reproductive success. Finally, we discuss future perspectives in a global change scenario.

\section{Consequences of Habitat Fragmentation on Microevolutionary Forces}

Habitat loss and fragmentation are tightly related processes, acknowledged amongst the most important drivers of biodiversity loss [13]. The interaction of those processes impacts natural habitats by (1) reducing area, (2) creating edge effects, (3) isolating habitat remnants from each other, and (4) interacting with the surrounding matrix [14]. Therefore, the differential sensitiveness to those factors determines the species subset that is able to persist in fragmented habitats [14]. Subsequently, when a continuous area becomes divided into smaller fragments, the subsequent compositional (i.e., species richness, abundances, and evenness) and demographic changes on the local resident populations are inescapable. Smaller local populations are usually less diverse and more prone to experience stochastic demographic processes, inbreeding depression and genetic drift [15], compromising gene flow and genetic diversity among them [16].

Fragmented habitats often exhibit a greater environmental heterogeneity as results of area, edge, and matrix effects $[17,18]$. Such increased heterogeneity causes important changes on the resource availability, quality, and spatial distribution $[12,19]$, creating a geographic gradient of environmental stress. Despite the fact that many species could show a plastic response to compensate situations of environmental stress [20], disturbed habitats may represent an opportunity for contemporary evolutionary processes [21]. Therefore, habitat fragmentation could significantly alter the evolutionary outcome in relatively short periods of time ( $\leq 100$ years), due to strong selective forces imposed by human activities [7, 22].

The novel scenario that habitat fragmentation imposes in the resident populations is also capable of altering antagonistic and mutualistic plant-animal interactions. Changes in abundance and composition of the interacting parties will certainly alter the microevolutionary forces that shape the coevolutionary process between plants and animals. Coevolution has a central role on community structuring, through associations among two or more species increasing the biological system complexity [12] as well as the fitness components of the interacting partners [23]. Under this idea, the study of coevolution should be a priority for the ecology research in fragmented habitats from an ecoevolutionary perspective [24-26]. Therefore, selective forces involved in plant-animal interactions could be affected by changes in abundance and interaction frequency (e.g., floral visit rate) of one or both interacting parties, altering the magnitude and direction of selection gradients acting upon them [7]. This could result in the selection of certain phenotypes over others (e.g., small seeds over the large ones; [27]), reshaping the community and their interaction networks on the long term $[28,29]$.
The fate of plant-animal interactions in a fragmented habitat depends on their tolerance, generalism, and capabilities of rapid evolution [7]. This set of "resilient traits" is favored by the degree of asymmetry (i.e., one specialist species interacting with two or more generalist counterparts) and specialization among ecological interactions. Thus, the degree of specialization and dependence on specialist species could determine the actual effect the loss of one interacting party would have on its counterpart [30]. Considering that most plant-animal interactions are asymmetric, the effects of losing one species could be less critical than for specialized symmetric relationships, since in asymmetric interactions at least one generalist mutualist remains, maintaining the interaction and therefore ensuring reproductive success [30].

Modified ecological interactions in fragmented habitats could affect the strength of coevolutionary interactions, disfavoring the persistence of coevolutionary hotspots $[3,23]$. Such situation would result into a mosaic of coevolution homogenization towards evolutionary cold spots [31]. Under this hypothetic scenario it is likely for plant-animal mutualisms to become disrupted in fragmented habitats because of changes in the evolutionary forces involved in frequencydependent selection events. If one or both mutualistic parties are not able to respond to the counterpart changes (i.e., to exert reinforcing coevolutionary selection), there are two possible outcomes: (1) the extinction of one or both species (according to their sensitiveness and specialization degree) or (2) shifting towards an antagonist relationship or the abandonment of the mutualism, choosing an autonomy path [7, 32] (Figure 1). Fragmentation imposes a vertiginous scenario for any ecological interaction, and only few genotypes would be able to sort the artificial selective filters created by human disturbances, making the extant populations even more prone to face demographic and genetic stochastic processes.

\section{Differential Effects of Habitat Fragmentation on Mutualistic and Antagonistic Plant-Animal Interactions}

There are hundreds of articles reporting changes in species richness and abundance at fragmented habitats [17, 33]. Recently, the interest in studying the effects of habitat fragmentation over ecological interactions has grown [34]. Diverse studies have documented that habitat fragmentation is capable of altering the guild structure of birds [35], as well as the richness and abundance of small mammals [36, 37] and insects $[38,39]$. They have also determined how such demographic effects could modify the intensity of herbivory and plant pathogen infection $[40,41]$, seed predation [42], insectivory [8], pollination [43,44], and seed dispersal $[6,45]$. This is particularly relevant for pollination and seed dispersal mutualisms, since they play a key role in biodiversity generation and maintenance [46]. Considering that at least $78 \%$ of the tropical and temperate tree species depend on animal counterparts for their reproductive success $[47,48]$, habitat fragmentation could seriously compromise those mutualisms [6]. 


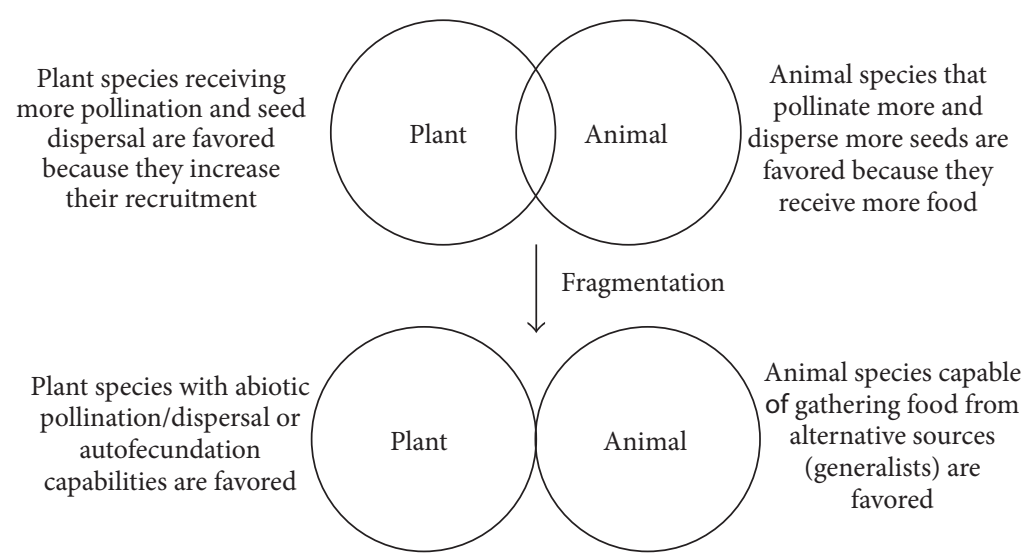

FIGURE 1: Schematic representation of habitat fragmentation effect on the abandonment of a plant-animal mutualism. The overlapping between circles represents interaction.

Besides the consequences of the disruption of plant-animal mutualisms, a less obvious scenario arises from the modification of plant-animal antagonisms in fragmented habitats. Small fragments are more exposed to herbivores and plant pathogens due to microclimate conditions favorable for their proliferation $[9,49]$. Despite the fact that herbivory rates often decrease with fragment size [50], small fragments are more exposed to novel antagonists (e.g., fungal diseases, parasitoids, galling, and mining insects) that arrive from the matrix and are strengthened by edge effects $[49,51,52]$. The spread of antagonists from the matrix could be strengthened by the use of biological corridors as a conservation strategy, since they may act as dispersion routes for diseases $[49,52]$. This situation is of critical importance when remnants of native habitat are surrounded by agricultural matrices, from which large generalist herbivores may act as pathogen vectors $[53,54]$. Further, since natural enemies are often absent at native habitat remnants, this situation might derive in plague outbreaks [55].

Altered plant-animal interactions in fragmented habitats could modify plant reproductive success (hence, plant fitness and its long-term persistence probabilities), depending on the direction and extent of how each individual interaction is modified. Plant species are expected to respond idiosyncratically to alterations in plant-animal interactions, related to lifehistory traits such as their tolerance to foliar damage, defenses against herbivores/pathogens, compatibility systems, degree of generalization, life form, and habitat specialization [40, 43].

Additionally, the abundance and composition (i.e., species richness) of plant and animal communities thriving in fragmented habitats will vary according to the differential species sensitiveness to the patch area, edge, isolation degree, and matrix quality $[14,56-58]$. Despite the fact that the ultimate fate of a given species (plant or animal) depends on its life history traits, as well as on its local adaptation and dispersal capabilities $[16,59]$, its performance in fragmented habitats will also depend on the changes experienced by their interacting counterparts, which could affect their persistence and/or reproductive success directly (e.g., disrupting the interaction) or indirectly (via coextinctions or through changes in the trophic relationships).

\section{Complex Relationships: A Multi-Interaction View}

Habitat fragmentation has demographic and microevolutionary consequences on plant-animal interactions, due to changes in abundance, the modification of the selective forces, and the subsequent changes in reproductive success [7]. However, there is an additional issue that should be taken into account when dealing with fragmented habitats, the role of multiple plant-animal interactions acting simultaneously.

Most studies have documented how a single plantanimal interaction is modified by habitat fragmentation, but studies addressing two or more interactions simultaneously are scarce in the literature [e.g., [60]]. We could expect an increase in plant fitness when a mutualism increases or an antagonism decreases and vice versa. However, a recent study [60] has demonstrated that the decrease of an antagonist interaction (herbivory) does not compensate the decrease of a mutualistic interaction (pollination), showing that the individual effects of ecological interactions are not additive in many cases [61].

Thinking in a more complex scenario, let us consider two mutualistic (pollination and seed dispersal) and two antagonistic interactions (herbivory and seed predation) acting simultaneously on a given plant species. From those four interactions, it will be possible to obtain at least 100 possible results in terms of reproductive success (Figure 2). Further, if a third interaction is added (e.g., defensive ants, mycorrhizae, parasites, and plant pathogens) the possible outcomes would increase exponentially. Unfortunately, there is little empirical evidence available for multiple plant-animal interactions in fragmented habitats because of the complexity of assessing many interactions simultaneously in the field, which constitutes indeed a great challenge for future studies.

Many articles have set ecological interactions into the community context [62-67], but their implications in fragmented habitats have been little discussed. In general terms, 
Mutualisms

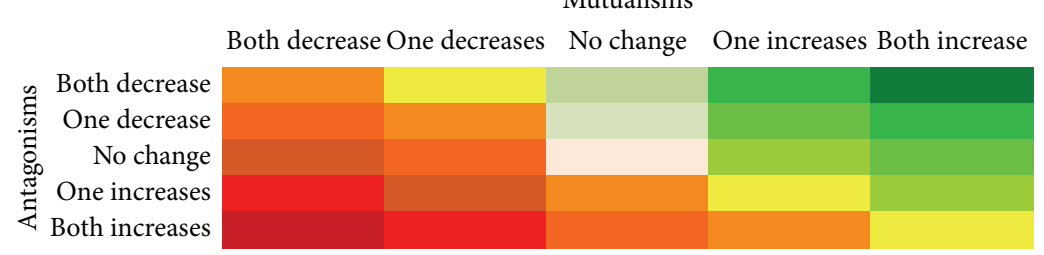

FIGURE 2: Expected consequences of disrupted plant-animal interactions due to habitat fragmentation. There are 100 possible combinations among the four interactions, two mutualisms (i.e., pollination and seed dispersal) and two antagonisms (herbivory and seed predation), considering the possibility that one or both mutualisms or antagonisms will increase, decrease, or remain unchanged. Green tones denote an increase into the plant reproductive success (as a proxy of fitness), whereas red tones denote a decrease.

the interaction among ecological interactions could be classified in four possible scenarios proposed by Strauss and Irwin [64], which may be applicable to fragmented habitats as well:

(1) antagonistic to antagonistic: the increase of certain herbivores could negatively affect other herbivores because of the triggering of defensive response from the plant;

(2) mutualistic to mutualistic: competition or facilitation among pollinators or dispersers, plant demographic changes could benefit certain pollinators and/or seed dispersers;

(3) antagonistic to mutualistic: herbivores produce damage to the plant and may alter certain phenotypic traits, affecting consequence pollination and/or seed dispersal;

(4) mutualistic to antagonistic: pollinators and/or dispersers can increase plant fitness, exposing it to greater herbivory pressure by increasing the supply for herbivores.

Among those four scenarios, the third one (antagonistic to mutualistic) may be the most critical scenario for plants thriving in fragmented habitats. For example, pollinators that respond to certain floral traits such as nectar guides [68] usually avoid those flowers damaged by herbivores [61, 69, $70]$, reducing the attractiveness of the damaged plant to the mutualists [71, 72]. Plants facing greater herbivory pressures are less pollinated and hence produce less seeds. Moreover, if pollinator abundance decreases in the fragments [73-75], effective pollination services that many plants receive would be dramatically reduced. Such situation might be critical in fragment edges where the incidence of antagonists tends to increase [51], compromising plant reproductive output. Recruitment of those plants depending on pollination vectors (usually autoincompatible plants) is expected to diminish because of the herbivory, both directly (tissue damage) and indirectly due to the reduction of the pollinator visit rates [69, $70,76]$, modifying plant fitness in many possible ways [77]. Moreover, the damage of certain key flower structure (e.g., nectar guides) could enhance this situation [78], especially if the flower damage goes beyond a damage threshold that makes the pollinators reluctant to visit the flowers [79].

\section{Future Perspectives: Are We Going to Nonanalog Communities?}

Diffuse and asymmetric coevolutionary interactions are more stable and less sensitive to habitat disturbance [3], determining - at least partially - the community resilience capabilities. Interacting parties in diffuse/asymmetric relationships are more prone to persist in spite of changes in the environment conditions and the demographic changes of their interacting parties. Even in an extreme scenario, they could evolve towards an autonomic strategy, breaking the mutualistic link if the costs of the interaction exceed the benefits (i.e., it is less costly not to interact). On the one hand, obligate or highly specialized mutualists are prone to primary and secondary extinctions [32]. On the other hand, antagonistic interactions also play a major role in shaping the plant community since those interactions, and particularly herbivory [80], constitute important regulation forces that limit the overgrowth of few generalist species that tend to dominate the community, reducing diversity and altering the trophic webs and, ultimately, ecosystem functionality $[9,81]$.

Changes in microevolutionary forces may influence the community composition and structure. However, their longterm effects are difficult to predict. As the coevolutionary processes have shaped plant-animal interactions for thousands of years, contemporary evolutionary phenomena caused by habitat fragmentation may lead to the establishment of new interactions or evolve towards autonomic strategies. Both outcomes may provoke a massive restructuration of the interaction networks within communities. Such restructuration might lead those plant and animal species remaining in fragmented habitats to evolve towards nonanalog communities in the long term future [82].

Finally, evolutionary and, particularly, coevolutionary implications related to plant-animal interactions should be explicitly considered aiming to reduce the current biodiversity loss rates. Despite the fact that fragmented habitats are currently considered into management plans, considering also the potential ecoevolutionary effects on ecological interactions and the quick spatiotemporal changes that affect them, it may have a positive contribution to maintain the natural ecosystems structure and dynamics. The inclusion of evolutionary issues on conservation plans is quite recent [24-26], and it has opened new research areas and courses of action. Nevertheless, its specific impact on fragmented 
habitats conservation is still emerging. It is necessary to conduct more research on this subject in order to elucidate the immediate and long-term consequences of the anthropic habitat modification on coevolutionary processes. Such information may allow us to make educated inferences about the possible fate of the remaining habitats worldwide, in changing ecological scenery because of the human action.

\section{Conflict of Interests}

The authors declare that there is no conflict of interests regarding the publication of this paper.

\section{Acknowledgments}

The authors are grateful to C. Botto-Mahan, C. GonzálezBrowne, and two anonymous reviewers for their comments and insights in a previous version of this paper. Francisco E. Fontúrbel and Maureen M. Murúa were supported by a doctoral fellowship granted by the Chilean Comisión de Investigación Científica y Tecnológica (CONICYT).

\section{References}

[1] C. R. Darwin, On the Origin of Species by Means of Natural Selection, or the Preservation of Favoured Races in the Struggle for Life, John Murray, London, UK, 1859.

[2] C. R. Darwin, On the Various Contrivances by Which British and Foreign Orchids are Fertilised by Insects, John Murray, London, UK, 1862.

[3] A. Pauw, J. Stofberg, and R. J. Waterman, "Flies and flowers in Darwin's race," Evolution, vol. 63, no. 1, pp. 268-279, 2009.

[4] D. H. Janzen, "When it is coevolution?" Evolution, vol. 34, no. 3, pp. 611-612, 1980.

[5] P. R. Ehrlich and P. H. Raven, "Butterflies and plants: a study in coevolution," Evolution, vol. 18, no. 4, pp. 586-608, 1964.

[6] M. A. Rodríguez-Cabal, M. A. Aizen, and A. J. Novaro, "Habitat fragmentation disrupts a plant-disperser mutualism in the temperate forest of South America," Biological Conservation, vol. 139, no. 1-2, pp. 195-202, 2007.

[7] E. T. Kiers, T. M. Palmer, A. R. Ives, J. F. Bruno, and J. L. Bronstein, "Mutualisms in a changing world: an evolutionary perspective," Ecology Letters, vol. 13, no. 12, pp. 1459-1474, 2010.

[8] P. L. González-Gómez, C. F. Estades, and J. A. Simonetti, "Strengthened insectivory in a temperate fragmented forest," Oecologia, vol. 148, no. 1, pp. 137-143, 2006.

[9] J. P. Arnold and C. R. Fonseca, "Herbivory, pathogens, and epiphylls in araucaria forest and ecologically-managed tree monocultures," Forest Ecology and Management, vol. 262, no. 6, pp. 1041-1046, 2011.

[10] K. Groppe, T. Steinger, B. Schmid, B. Baur, and T. Boller, "Effects of habitat fragmentation on choke disease (Epichloë bromicola) in the grass Bromus erectus," Journal of Ecology, vol. 89, no. 2, pp. 247-255, 2001.

[11] K. McGarigal and S. A. Cushman, "Comparative evaluation of experimental approaches to the study of habitat fragmentation effects," Ecological Applications, vol. 12, no. 2, pp. 335-345, 2002.

[12] P. H. Thrall, M. E. Hochberg, J. J. Burdon, and J. D. Bever, "Coevolution of symbiotic mutualists and parasites in a community context," Trends in Ecology and Evolution, vol. 22, no. 3, pp. 120126, 2007

[13] L. Fahrig, "Relative effects of habitat loss and fragmentation on population extinction," Journal of Wildlife Management, vol. 61, no. 3, pp. 603-610, 1997.

[14] R. M. Ewers and R. K. Didham, "Confounding factors in the detection of species responses to habitat fragmentation," Biological Reviews of the Cambridge Philosophical Society, vol. 81, no. 1, pp. 117-142, 2006.

[15] L. F. Keller and D. M. Waller, "Inbreeding effects in wild populations," Trends in Ecology and Evolution, vol. 17, no. 5, pp. 230 241, 2002.

[16] M. L. Lancaster, A. C. Taylor, S. J. B. Cooper, and S. M. Carthew, "Limited ecological connectivity of an arboreal marsupial across a forest/plantation landscape despite apparent resilience to fragmentation," Molecular Ecology, vol. 20, no. 11, pp. 22582271, 2011.

[17] H. Andrén, "Effects of habitat fragmentation on birds and mammals in landscapes with different proportions of suitable habitat: a review," Oikos, vol. 71, no. 3, pp. 355-366, 1994.

[18] L. Fahrig, "Effects of habitat fragmentation on biodiversity," Annual Review of Ecology, Evolution, and Systematics, vol. 34, pp. 487-515, 2003.

[19] J. M. Herrera, J. M. Morales, and D. García, "Differential effects of fruit availability and habitat cover for frugivore-mediated seed dispersal in a heterogeneous landscape," Journal of Ecology, vol. 99, no. 5, pp. 1100-1107, 2011.

[20] G. Bowman, C. Perret, S. Hoehn, D. J. Galeuchet, and M. Fischer, "Habitat fragmentation and adaptation: a reciprocal replant-transplant experiment among 15 populations of Lychnis flos-cuculi," Journal of Ecology, vol. 96, no. 5, pp. 1056-1064, 2008.

[21] N. G. Hairston Jr., S. P. Ellner, M. A. Geber, T. Yoshida, and J. A. Fox, "Rapid evolution and the convergence of ecological and evolutionary time," Ecology Letters, vol. 8, no. 10, pp. 1114-1127, 2005.

[22] M. Murúa, C. Espinoza, R. Bustamante, V. H. Marín, and R. Medel, "Does human-induced habitat transformation modify pollinator-mediated selection? A case study in Viola portalesia (Violaceae)," Oecologia, vol. 163, no. 1, pp. 153-162, 2010.

[23] M. Tobler and I. Schlupp, "Expanding the horizon: the Red Queen and potential alternatives," Canadian Journal of Zoology, vol. 86, no. 8, pp. 765-773, 2008.

[24] M. T. Kinnison and N. G. Hairston Jr., "Eco-evolutionary conservation biology: contemporary evolution and the dynamics of persistence," Functional Ecology, vol. 21, no. 3, pp. 444-454, 2007.

[25] M. T. Kinnison, A. P. Hendry, and C. A. Stockwell, "Contemporary evolution meets conservation biology II: impediments to integration and application," Ecological Research, vol. 22, no. 6, pp. 947-954, 2007.

[26] C. A. Stockwell, A. P. Hendry, and M. T. Kinnison, "Contemporary evolution meets conservation biology," Trends in Ecology and Evolution, vol. 18, no. 2, pp. 94-101, 2003.

[27] M. Galetti, R. Guevara, M. C. Côrtes et al., "Functional extinction of birds drives rapid evolutionary changes in seed size," Science, vol. 340, no. 6136, pp. 1086-1090, 2013.

[28] E. M. Albert, M. A. Fortuna, J. A. Godoy, and J. Bascompte, "Assessing the robustness of networks of spatial genetic variation," Ecology Letters, vol. 16, no. 1, pp. 86-93, 2013. 
[29] J. Bascompte and P. Jordano, "Plant-animal mutualistic networks: the architecture of biodiversity," Annual Review of Ecology, Evolution, and Systematics, vol. 38, pp. 567-593, 2007.

[30] L. Ashworth, R. Aguilar, L. Galetto, and M. A. Aizen, "Why do pollination generalist and specialist plant species show similar reproductive susceptibility to habitat fragmentation?" Journal of Ecology, vol. 92, no. 4, pp. 717-719, 2004.

[31] J. N. Thompson, "Specific hypotheses on the geographic mosaic of coevolution," American Naturalist, vol. 153, no. S5, pp. S1-S14, 1999.

[32] J. L. Sachs and E. L. Simms, "Pathways to mutualism breakdown," Trends in Ecology and Evolution, vol. 21, no. 10, pp. 585$592,2006$.

[33] C. Gascon, T. E. Lovejoy, R. O. Bierregaard Jr. et al., "Matrix habitat and species richness in tropical forest remnants," Biological Conservation, vol. 91, no. 2-3, pp. 223-229, 1999.

[34] T. Tscharntke and R. Brandl, "Plant-insect interactions in fragmented landscapes," Annual Review of Entomology, vol. 49, no. 1, pp. 405-430, 2004.

[35] J. Barlow, C. A. Peres, L. M. P. Henriques, P. C. Stouffer, and J. M. Wunderle, "The responses of understorey birds to forest fragmentation, logging and wildfires: an Amazonian synthesis," Biological Conservation, vol. 128, no. 2, pp. 182-192, 2006.

[36] D. A. Kelt, "Differential effects of habitat fragmentation on birds and mammals in Valdivian temperate rainforests," Revista Chilena de Historia Natural, vol. 74, no. 4, pp. 769-777, 2001.

[37] R. Pardini, S. M. De Souza, R. Braga-Neto, and J. P. Metzger, "The role of forest structure, fragment size and corridors in maintaining small mammal abundance and diversity in an Atlantic forest landscape," Biological Conservation, vol. 124, no. 2, pp. 253-266, 2005.

[38] R. K. Didham, J. Ghazoul, N. E. Stork, and A. J. Davis, "Insects in fragmented forests: a functional approach," Trends in Ecology and Evolution, vol. 11, no. 6, pp. 255-260, 1996.

[39] A. . Grez, T. Zaviezo, L. Tischendorf, and L. Fahrig, "A transient, positive effect of habitat fragmentation on insect population densities," Oecologia, vol. 141, no. 3, pp. 444-451, 2004.

[40] A. E. Arnold and N. M. Asquith, "Herbivory in a fragmented tropical forest: patterns from islands at Lago Gatún, Panama," Biodiversity and Conservation, vol. 11, no. 9, pp. 1663-1680, 2002.

[41] P. A. Vásquez, A. A. Grez, R. O. Bustamante, and J. A. Simonetti, "Herbivory, foliar survival and shoot growth in fragmented populations of Aristotelia chilensis," Acta Oecologica, vol. 31, no. 1, pp. 48-53, 2007.

[42] D. S. Donoso, A. A. Grez, and J. A. Simonetti, "Effects of forest fragmentation on the granivory of differently sized seeds," Biological Conservation, vol. 115, no. 1, pp. 63-70, 2004.

[43] R. Aguilar, L. Ashworth, L. Galetto, and M. A. Aizen, "Plant reproductive susceptibility to habitat fragmentation: review and synthesis through a meta-analysis," Ecology Letters, vol. 9, no. 8, pp. 968-980, 2006.

[44] M. A. Aizen and P. Feinsinger, "Forest fragmentation, pollination, and plant reproduction in a chaco dry forest, Argentina," Ecology, vol. 75, no. 2, pp. 330-351, 1994.

[45] N. J. Cordeiro and H. F. Howe, "Low recruitment of trees dispersed by animals in African forest fragments," Conservation Biology, vol. 15, no. 6, pp. 1733-1741, 2001.

[46] J. N. Thompson, The Coevolutionary Process, The Chicago University Press, Chicago, Ill, USA, 1994.

[47] F. Howe and J. Smallwood, "Ecology of seed dispersal.," Annual review of ecology and systematics. Volume 13, pp. 201-228, 1982.
[48] J. Ollerton, A. Stott, E. Allnutt, S. Shove, C. Taylor, and E. Lamborn, "Pollination niche overlap between a parasitic plant and its host," Oecologia, vol. 151, no. 3, pp. 473-485, 2007.

[49] B. L. Johnson and N. M. Haddad, "Edge effects, not connectivity, determine the incidence and development of a foliar fungal plant disease," Ecology, vol. 92, no. 8, pp. 1551-1558, 2011.

[50] G. Valladares, A. Salvo, and L. Cagnolo, "Habitat fragmentation effects on trophic processes of insect-plant food webs," Conservation Biology, vol. 20, no. 1, pp. 212-217, 2006.

[51] D. M. Evans, N. E. Turley, and J. J. Tewksbury, "Habitat edge effects alter ant-guard protection against herbivory," Landscape Ecology, vol. 28, no. 9, pp. 1743-1754, 2013.

[52] L. L. Sullivan, B. L. Johnson, L. A. Brudvig, and N. M. Haddad, "Can dispersal mode predict corridor effects on plant parasites?” Ecology, vol. 92, no. 8, pp. 1559-1564, 2011.

[53] A. G. Auffret and J. Plue, "Scale-dependent diversity effects of seed dispersal by a wild herbivore in fragmented grasslands," Oecologia, vol. 175, no. 1, pp. 305-313, 2014.

[54] E. S. Jules and P. Shahani, "A broader ecological context to habitat fragmentation: why matrix habitat is more important than we thought," Journal of Vegetation Science, vol. 14, no. 3, pp. 459-464, 2003.

[55] A. Kruess and T. Tscharntke, "Habitat fragmentation, species loss, and biological control," Science, vol. 264, no. 5165, pp. 15811584, 1994.

[56] D. T. Bolger, A. C. Alberts, R. M. Sauvajot et al., "Response of rodents to habitat fragmentation in coastal southern California," Ecological Applications, vol. 7, no. 2, pp. 552-563, 1997.

[57] T. D. Castellón and K. E. Sieving, "Landscape history, fragmentation, and patch occupancy: models for a forest bird with limited dispersal," Ecological Applications, vol. 16, no. 6, pp. 2223-2234, 2006.

[58] K. R. Crooks, "Relative sensitivities of mammalian carnivores to habitat fragmentation," Conservation Biology, vol. 16, no. 2, pp. 488-502, 2002.

[59] T. J. Kawecki and D. Ebert, "Conceptual issues in local adaptation," Ecology Letters, vol. 7, no. 12, pp. 1225-1241, 2004.

[60] C. E. Valdivia, A. Bahamondez, and J. A. Simonetti, "Negative effects of forest fragmentation and proximity to edges on pollination and herbivory of Bomarea salsilla (Alstroemeriaceae)," Plant Ecology and Evolution, vol. 144, no. 3, pp. 281-287, 2011.

[61] N. Pohl, G. Carvallo, C. Botto-Mahan, and R. Medel, "Nonadditive effects of flower damage and hummingbird pollination on the fecundity of Mimulus luteus," Oecologia, vol. 149, no. 4, pp. 648-655, 2006.

[62] W. S. Armbuster, "Exaptations link evolution of plant-herbivore and plant-pollinator interactions: a phylogenetic inquiry," Ecology, vol. 78, no. 6, pp. 1661-1672, 1997.

[63] C. M. Herrera, "Measuring the effects of pollinators and herbivores: evidence for non-additivity in a perennial herb," Ecology, vol. 81, no. 8, pp. 2170-2176, 2000.

[64] S. Y. Strauss and R. E. Irwin, "Ecological and evolutionary consequences of multispecies plant-animal interactions," Annual Review of Ecology, Evolution, and Systematics, vol. 35, pp. 435466, 2004.

[65] S. Y. Strauss, "Indirect effects in community ecology: their definition, study and importance," Trends in Ecology and Evolution, vol. 6, no. 7, pp. 206-210, 1991.

[66] S. Y. Strauss, "Floral characters link herbivores, pollinators, and plant fitness," Ecology, vol. 78, no. 6, pp. 1640-1645, 1997. 
[67] S. Y. Strauss and W. S. Armbruster, "Linking herbivory and pollination: new perspectives on plant and animal ecology and evolution," Ecology, vol. 78, no. 6, pp. 1617-1618, 1997.

[68] R. Medel, C. Botto-Mahan, and M. Kalin-Arroyo, "Pollinatormediated selection on the nectar guide phenotype in the Andean monkey flower, Mimulus luteus," Ecology, vol. 84, no. 7, pp. 1721-1732, 2003.

[69] G. A. Krupnick and A. E. Weis, "The effect of floral herbivory on male and female reproductive success in Isomeris arborea," Ecology, vol. 80, no. 1, pp. 135-149, 1999.

[70] G. A. Krupnick, A. E. Weis, and D. R. Campbell, "The consequences of floral herbivory for pollinator service to Isomeris arborea," Ecology, vol. 80, no. 1, pp. 125-134, 1999.

[71] K. Lehtilä and S. Y. Strauss, "Leaf damage by herbivores affects attractiveness to pollinators in wild radish, Raphanus raphanistrum," Oecologia, vol. 111, no. 3, pp. 396-403, 1997.

[72] S. Y. Strauss, J. K. Conner, and S. L. Rush, "Foliar herbivory affects floral characters and plant attractiveness to pollinators: implications for male and female plant fitness," The American Naturalist, vol. 147, no. 6, pp. 1098-1107, 1996.

[73] O. Barbosa and P. A. Marquet, "Effects of forest fragmentation on the beetle assemblage at the relict forest of Fray Jorge, Chile," Oecologia, vol. 132, no. 2, pp. 296-306, 2002.

[74] K. F. Davies and C. R. Margules, "Effects of habitat fragmentation on carabid beetles: experimental evidence," Journal of Animal Ecology, vol. 67, no. 3, pp. 460-471, 1998.

[75] C. E. Valdivia, J. A. Simonetti, and C. A. Henríquez, "Depressed pollination of Lapageria rosea Ruiz et Pav. (Philesiaceae) in the fragmented temperate rainforest of southern South America," Biodiversity and Conservation, vol. 15, no. 5, pp. 1845-1856, 2006.

[76] Y. J. Cardel and S. Koptur, "Effects of florivory on the pollination of flowers: an experimental field study with a perennial plant," International Journal of Plant Sciences, vol. 171, no. 3, pp. 283292, 2010.

[77] A. C. McCall and R. E. Irwin, "Florivory: the intersection of pollination and herbivory," Ecology Letters, vol. 9, no. 12, pp. 1351$1365,2006$.

[78] C. Botto-Mahan, P. A. Ramírez, C. G. Ossa, R. Medel, M. OjedaCamacho, and A. V. González, "Floral herbivory affects female reproductive success and pollinator visitation in the perennial herb Alstroemeria Ligtu (Alstroemeriaceae)," International Journal of Plant Sciences, vol. 172, no. 9, pp. 1130-1136, 2011.

[79] R. Cares-Suárez, T. Poch, R. F. Acevedo et al., "Do pollinators respond in a dose-dependent manner to flower herbivory? An experimental assessment in Loasa tricolor (Loasaceae)," Gayana: Botanica, vol. 68, no. 2, pp. 176-181, 2011.

[80] R. Leimu, A. Muola, L. Laukkanen, A. Kalske, N. Prill, and P. Mutikainen, "Plant-herbivore coevolution in a changing world," Entomologia Experimentalis et Applicata, vol. 144, no. 1, pp. 3-13, 2012.

[81] F. Peter, D. G. Berens, and N. Farwig, "Effects of local tree diversity on herbivore communities diminish with increasing forest fragmentation on the landscape scale," PLoS ONE, vol. 9, no. 4, Article ID e95551, 2014.

[82] D. Fox, "Back to the no-analog future?" Science, vol. 316, no. 5826, pp. 823-825, 2007. 

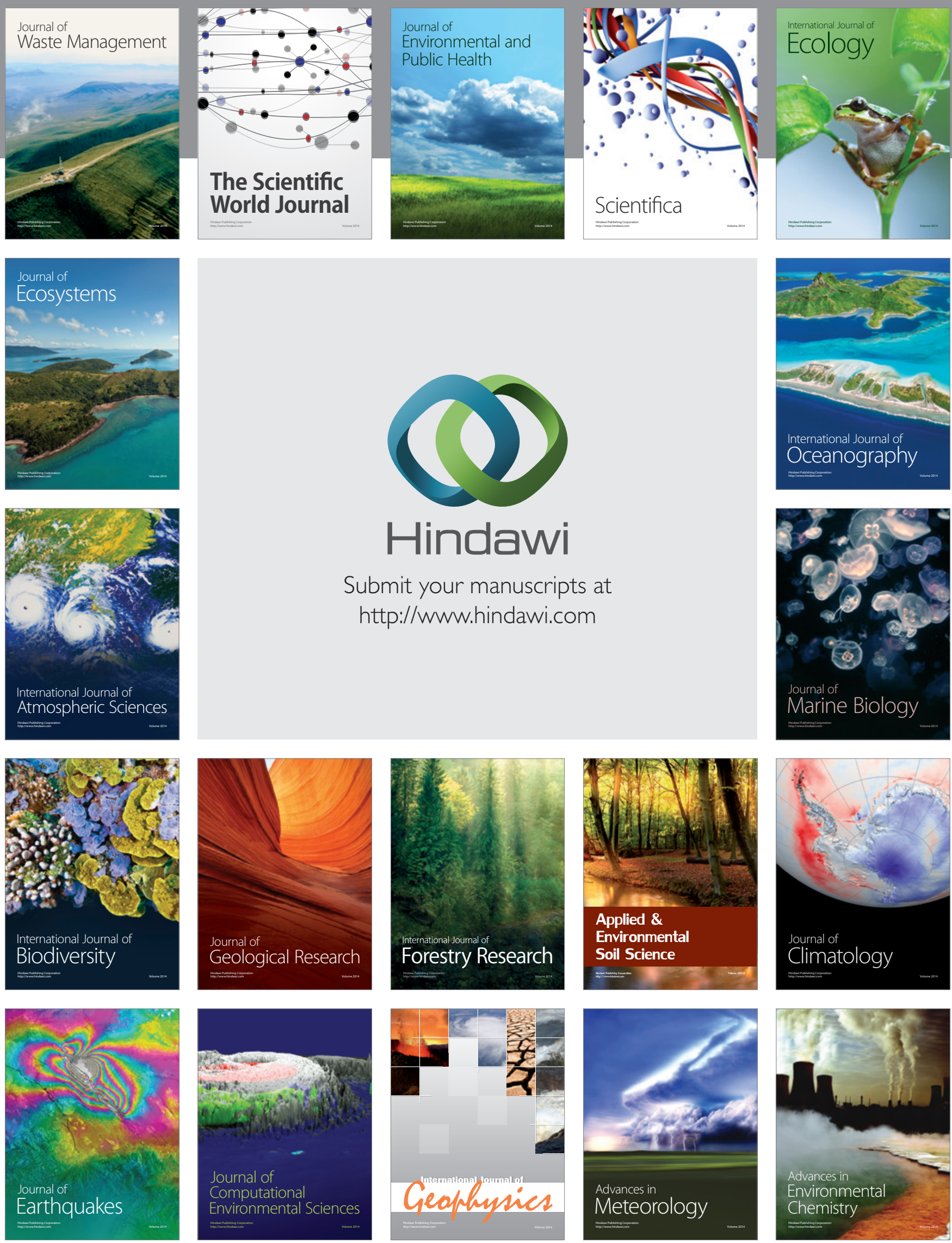